\title{
Psicologia, diretrizes curriculares e processos educativos na Amazônia: um estudo da formação de psicólogos
}

\author{
Tânia Suely Azevedo Brasileiro \\ Marilene Proença Rebello de Souza
}

\begin{abstract}
Resumo
Este estudo objetiva analisar a formação de psicólogos frente às Diretrizes Curriculares Nacionais para os Cursos de Psicologia no que tange aos processos educativos. Realizamos revisão da literatura pertinente ao tema, pesquisa documental e empírica com alunos, professores e coordenador de curso, utilizando questionário, entrevistas e adotando a estratégia de triangulação a partir das categorias: perfil sociocultural; nível de conhecimento acerca das mudanças oriundas das Diretrizes para o curso de Psicologia; percepção na qualidade da prática docente; nível de satisfação com relação à própria formação universitária, tomando como referência os conhecimentos, habilidades e competências adquiridas. Apresenta contribuições para a compreensão da formação de psicólogos no campo da educação na Amazônia no Ensino Superior, centrada na construção de um profissional de pensamento e prática críticos, capaz de analisar as transformações nos vários contextos educacionais e escolares, utilizando referenciais que permitam a compreensão do fenômeno educativo na sua complexidade.
\end{abstract}

Palavras-chave: Formação do psicólogo, psicologia escolar, ensino superior.

\section{Psychology, curriculum and educational processes in the Amazon: a case study of psychology students}

\begin{abstract}
In this study we aim at analyzing the psychologist education related to National Curriculum Guidelines (PCN) for the Psychology course when referring to the educational knowledge process. We have anylized the literature related to the theme, as well as we did a documental and empirical research with students, professors, course coordinators, by using questionnaires, interviews and by adopting a triangle strategy, starting from the categories: socio-cultural profile, level of knowledge around the changes coming from the Curriculum guidelines for the course of Psychology; perception of the quality of the teaching practice and level of satisfaction related to the university education considering the knowledge and skills acquired from it. We propose some contributions to the educational psychologist in the field of Education in higher education in the Amazon region. This contribution should be centered on the constructing of a critical thinking and practice, capable of analyzing the transformation, visible in several educational and school contexts, based on concepts that favor the understanding of the complex educative phenomenon.
\end{abstract}

Keywords: Psychologist education, school psychology, higher education.

\section{Psicología, directrices curriculares y procesos educativos en la Amazonía: un estudio de la formación de psicólogos}

\begin{abstract}
Resumen
Este estudio tiene el objetivo de analizar la formación de psicólogos frente a las Directrices Curriculares Nacionales para los Cursos de Psicología en lo que dice respecto a los procesos educativos. Realizamos revisión de la literatura pertinente al tema, investigación documental y empírica con alumnos, profesores, coordinador de curso. Se utilizó cuestionario, entrevistas y se adoptó la estrategia de triangulación, a partir de las categorías: perfil sociocultural; nivel de conocimiento acerca de los cambios oriundos de las Directrices para el curso de Psicología; percepción de la calidad de práctica docente; nivel de satisfacción en relación a la propia formación universitaria, tomando como referencia los conocimientos, habilidades y competencias adquiridas. Presentamos contribuciones para la comprensión de la formación de psicólogos en el campo de la educación en la Amazonía en la enseñanza superior, centrada en la construcción de un profesional de pensamiento y práctica críticos, capaz de analizar las transformaciones en los varios contextos educacionales y escolares, utilizando referenciales que permitan la comprensión del fenómeno educativo en su complejidad.
\end{abstract}

Palabras clave: Formación del psicólogo, psicología escolar, educación superior. 


\section{Introdução}

Atualmente, há um consenso entre os pesquisadores brasileiros de que a Psicologia não mais se restringe ao modelo clínico, centrado no atendimento individual, baseando apenas em aspectos intrapsíquicos as explicações para a complexidade das ações e intenções humanas (Tanamachi, 2002). Nas várias áreas em que o psicólogo atua, constatase a discussão da importância de um trabalho social, em equipes multiprofissionais, utilizando referenciais teóricometodológicos que busquem responder, de alguma maneira, aos desafios postos pela realidade social na qual o indivíduo está inserido ${ }^{1}$.

No campo da Psicologia Escolar e Educacional, os pesquisadores da área são praticamente unânimes em defender uma formação centrada na construção de um profissional de pensamento e prática críticos, capaz de analisar as transformações vigentes nos vários contextos educacionais e escolares, trabalhando coletivamente, a partir de uma perspectiva ético-política, utilizando referenciais que permitam a compreensão do fenômeno educativo na sua complexidade, considerando suas múltiplas determinações: sociais, políticas, institucionais e individuais ${ }^{2}$.

No caso brasileiro, a formação de psicólogos é regida pelas Diretrizes Curriculares Nacionais. Este conjunto de diretrizes para o curso de Psicologia foi aprovado em 2004, fazendo com que as instituições de formação em nível superior tenham que implementá-las, com todas as adequações e modificações que este novo modelo requer aos currículos e estruturas de curso até então vigentes. Esse momento coincide com a expansão de vagas no Ensino Superior, incrementada por uma nova política pública instituída em nível federal que privilegia a abertura de vagas e recursos para instituições privadas, conforme dados do MEC/INEP (2007).

Em 2007, o Grupo de Trabalho em Psicologia Escolar e Educacional da ANPEPP organizou importante publicação intitulada "Formação em Psicologia Escolar: realidades e perspectivas" - coordenada pelo Prof. Dr. Herculano Ricardo Campos (2007), cujos capítulos remetem a este importante momento da formação. Neste livro, tem especial destaque o capítulo de Marinho-Araújo (2007), intitulado A psicologia escolar nas diretrizes curriculares: espaços criados, desafios instalados.

Esta pesquisa insere-se neste momento histórico da implantação das novas Diretrizes Curriculares Nacionais na formação de psicólogos, estabelecendo o recorte temático em uma das possibilidades de ênfases a ser trabalhada por estas Diretrizes e que se refere aos processos educativos e

1 Esta constatação pode ser verificada na produção recente da Psicologia, fruto de grupos de pesquisa no Brasil e de produções oriundas dos grupos de Trabalho da ANPEPP - Associação Nacional de Pesquisa e Pós-Graduação em Psicologia.

2 O V Congresso Nacional Norte-Nordeste em Psicologia, realizado em Maceió, em 2007, organizou publicação intitulada "A produção na diversidade: compromissos éticos e políticos em Psicologia" que muito bem retrata parte das discussões recentes na área. à atuação do psicólogo no campo da educação. Para tanto, conta com a participação de pesquisadores dos Estados de São Paulo, Minas Gerais e Rondônia, possibilitando uma análise ampliada da formação/prática profissional em Psicologia no campo da Educação em nosso país.

O objetivo geral da pesquisa é analisar a formação dada aos futuros psicólogos nos Cursos de Graduação em Psicologia quanto à ênfase nos processos educativos, tendo em vista as novas Diretrizes Curriculares Nacionais vigentes em Psicologia.

Com relação aos objetivos específicos do estudo, elaboramos os seguintes: levantar e analisar a literatura estudada na área da Psicologia Escolar e Educacional, tendo como categorias de análise elementos que compõem uma perspectiva crítica do trabalho do psicólogo no campo da educação; analisar os documentos oficiais produzidos pelos cursos de formação e que se referem à dimensão educativa do trabalho do psicólogo; levantar os elementos que compõem o pensamento e a prática docente universitária no que se refere à formação/atuação do psicólogo no campo da educação a partir da percepção de coordenadores, professores e alunos do $4^{\circ}$ e $5^{\circ}$ anos de cursos de Psicologia.

Neste artigo, damos destaque à pesquisa realizada na região Norte, mais especificamente na Universidade Federal de Rondônia - UNIR, primeira a oferecer o curso de formação de psicólogo em todo o Estado. Consideramos que estudos desta natureza nos revelam diferentes realidades brasileiras, de forma a ampliar a compreensão das questões da formação/prática profissional na área de Psicologia no país.

\section{A formação de psicólogos no Brasil}

A formação de psicólogos no Brasil fortaleceu-se a partir da Regulamentação Profissional que ocorreu em 1962 (Lei $n^{\circ} 4119$ ). Nos últimos 46 anos, o crescimento da Psicologia foi vertiginoso, partindo da formação de 78 psicólogos em São Paulo, na Faculdade de Filosofia, Letras e Ciências Humanas da USP, para aproximadamente 160 mil profissionais em todo o Brasil. Desde 1971, com a Lei 5766, todo psicólogo tem que se registrar em seu Conselho Profissional para exercer a profissão. Para tanto, precisa estar inscrito em um Conselho de Psicologia em seu Estado de exercício profissional (Conselhos Regionais). A finalidade dos Conselhos Profissionais é de orientar e fiscalizar o exercício profissional, bem como contribuir para o desenvolvimento da Psicologia como ciência e profissão de forma a garantir à sociedade a qualidade técnica e ética dos serviços prestados pelos profissionais de Psicologia em todo o país. O Sistema Conselhos é constituído por um Conselho Federal de Psicologia e 17 Conselhos Regionais, que devem seguir o mesmo Código de Ética Profissional ${ }^{3}$ e o Código de Processamento Disciplinar (Resolução 06/2007) ${ }^{4}$.

3 O Código de Ética Profissional foi criado em 1979, pela Resolução 029/79; revisado em 1987, pela resolução 02/1987 e mais recentemente substituído pela Resolução 010/2005.

4 A complexidade do exercício profissional pode ser observada por 
A configuração política e econômica do Estado brasileiro fez com que grande parte dos cursos de formação de Psicologia fosse organizada no Estado de São Paulo. Atualmente é o Estado que possui em torno de $35 \%$ dos psicólogos brasileiros exercendo a profissão, bem como aproximadamente $1 / 3$ dos cursos de Psicologia do Brasil (www. abepsi.org.br).

Conforme analisam Checchia e Souza (2003), três importantes publicações podem ser consideradas como as que permitem contemplar as principais análises a respeito da formação de psicólogos. São elas: o estudo pioneiro de Mello (1975) sobre os cursos de formação em Psicologia em São Paulo; a publicação do Conselho Federal de Psicologia (1988) a respeito de "Quem é o psicólogo brasileiro?" e o livro Psicólogo Brasileiro: práticas emergentes e desafios para a formação, organizado por Bastos e Achcar (1994) a pedido do Conselho Federal de Psicologia.

Uma breve retrospectiva dessas três publicações, com base nas discussões apresentadas por Checchia e Souza (2003), permite-nos analisar, mesmo que de maneira sucinta, o quadro de formação profissional no Brasil. Como analisa Mello (1975), os cursos de Psicologia, em seus primórdios, optam por um modelo de formação centrado em uma concepção profissional clínica e de profissional liberal, priorizando o atendimento individual em consultórios particulares, inspirada no modelo médico. As disciplinas presentes no currículo enfatizavam a formação nas áreas de psicodiagnóstico, avaliação psicológica e psicoterapias. Esse quadro se mantém nos anos 1960,1970, fortalecidos por um período político de exceção, sob a égide de uma ditadura militar, interferindo diretamente na constituição das ideias e das ações profissionais em todas as áreas do conhecimento, incluindo a Psicologia ${ }^{5}$. As primeiras mudanças nesse quadro vão acontecer somente em meados dos anos 1980, como analisam os demais trabalhos citados, no momento também em que se configura o movimento de abertura política e a luta pela democratização do Estado brasileiro e a implantação do Sistema Único de Saúde no Brasil ${ }^{6}$. Tais mudanças centram-se nas discussões a respeito das finalidades da profissão e da prática profissional, bem como veiculam críticas importantes à formação profissional e que terão seus reflexos nos anos 1990, mais diretamente, como tentaremos mostrar a seguir.

meio das várias Resoluções e Documentos produzidos pelo Conselho Federal de Psicologia em consonância com os Conselhos Regionais. Estes documentos são disponibilizados no site do Conselho Federal no endereço www.pol.org.br.

5 A análise preciosa desse momento histórico da Psicologia no campo da formação e da profissão é apresentada por Coimbra em sua tese de doutorado, defendida no Instituto de Psicologia da USP e denominada "Gerentes da Ordem: algumas práticas "Psi" nos aos 70 no Brasil", 1992.

6 O processo de discussão e implementação do Sistema Único de Saúde brasileiro é constituído a partir da Carta de Ottawa de 1986, ocasião em que aconteceu a Primeira Conferência Internacional sobre Promoção de Saúde.
Com relação à reforma psiquiátrica, movimento iniciado no final da década de 70 e que se estendeu até 90 , foi um espaço privilegiado para discussão do modelo de atendimento médico dado aos portadores de transtornos mentais e também os psicólogos iniciaram uma discussão sobre seu papel nestes casos. Paralelamente, o modelo médico dentro da Psicologia também estava sendo discutido no âmbito da Psicologia Educacional e Escolar por meio de críticas como as feitas por Patto (1981) e, posteriormente, outros trabalhos endossaram a necessidade de mudança do perfil do psicólogo e sua prática.

As mudanças que se apresentam no perfil profissional e na formação profissional devem-se a quê? Esta é uma pergunta que vários estudos no Brasil vêm tentando responder. No trabalho de 1988, Botomé (citado por Checchia \& Souza, 2003), discute a mudança do olhar da Psicologia sobre o seu objeto de estudo por meio da introdução de críticas que vieram principalmente do pensamento crítico sociológico à compreensão do pensamento psicológico ${ }^{7}$ e da introdução de discussões no campo da Psicologia advindas do que se denominou Movimento Institucionalista e da Psicologia Institucional ${ }^{8}$, de maneira a destacar a importância da multidisciplinaridade ou da interdisciplinaridade. No bojo desta discussão, os currículos dos cursos de Psicologia passam a ser o alvo das principais críticas pelo fato de excluírem vários aspectos da realidade social do país e por ensinarem uma Psicologia dita neutra e científica, com bases claramente positivistas e a-históricas. Para exemplificar, o trabalho do psicólogo escolar e educacional baseava-se quase exclusivamente em determinar o Q.I. ou a deficiência de crianças em idade escolar para alocação em classes especiais por meio de testes psicológicos baseados no modelo psicométrico e clínico.

Assim sendo, os anos 1990 inauguram um conjunto de ações que passam a acontecer nos planos político ${ }^{9} \mathrm{e}$ social brasileiros e que influenciam a profissão, bem como fermentam a discussão teórico-metodológica nas diversas áreas de atuação profissional. Esse momento de discussão e problematização da Psicologia retratado por Bastos e Achcar (1994) centra a análise de tais mudanças em três grandes áreas clássicas de atuação profissional: Clínica, Escolar e Organizacional e do Trabalho. Contribuíram com este levantamento professores das principais universidades e faculdades de Psicologia do Brasil, possibilitando um perfil

7 Note-se que a tese de Maria Helena Souza Patto que analisa este tema foi defendida em 1981 com o título Psicologia e ideologia : reflexões sobre a psicologia escolar, orientada pela Profa. Eclea Bosi. 8 No rastro dos "cavalos do diabo": memória e história para uma reinvenção de percursos do paradigma do grupalismoinstitucionalismo no Brasil é a tese de doutorado de Heliana Conde Rodrigues que analisa esse importante movimento latino-americano e sua presença no Brasil, 2002.

9 Aprovação, em 1988, de novo texto da Constituição Brasileira e que, pelo seu alcance social, foi denominada de "Constituição Cidadã". 
bastante completo da discussão sobre a formação e atuação do psicólogo.

Com relação à Psicologia Clínica, Lo Bianco, Bastos, Nunes e Silva (1994) analisam que, a partir de meados dos anos 1980, há mudanças tanto nos referenciais teóricos utilizados, quanto nas práticas veiculadas na atuação profissional. Essas mudanças referem-se à ampliação do modelo de atendimento psicológico predominantemente centrado nos consultórios (anos 70) para instituições de atenção básica e secundária, bem como os questionamentos advindos da Reforma Psiquiátrica e Luta Antimanicomial e suas repercussões no atendimento psicológico. No campo dos referenciais para esse trabalho, segundo os autores, há um questionamento do modelo que explica os fenômenos psíquicos como tão somente individuais para considerar a "inserção social" do sujeito. Destacam, ainda, a grande demanda de problemas escolares presentes no campo da Saúde, bem como a necessidade de atuação em um nível preventivo de atenção primária. No que concerne à formação profissional, as autoras, conforme referenda o texto de Checchia e Souza (2003), consideram que as concepções vigentes implicam ações no plano da formação em dois eixos: "dos requisitos e competências necessários para a realização de um trabalho profissional de qualidade e as características e estrutura de formação profissional que possibilitem efetivamente mudanças na prática clínica" (p.116, grifos das autoras). Aspectos tais como a contextualização do fenômeno psíquico, a observação, a estruturação do ato pedagógico que possibilite a aquisição dessas competências e habilidades, a crítica teórico-metodológica, a inclusão de conteúdos advindos da Antropologia, da Filosofia e da Sociologia, o trabalho em equipes multiprofissionais e a relação universidade-comunidade foram abordados como fundamentais no plano da formação profissional.

No que se refere à área de Psicologia Organizacional e do Trabalho, as discussões também têm se aprofundado nas vertentes da globalização e das novas formas de gestão, bem como nas críticas ao modelo de acúmulo de capital e na criação das gestões cooperativas e de economia solidária. O trabalho do psicólogo transcende a tradicional visão de recursos humanos e de seleção de pessoal, participando mais amplamente em outras dimensões da relação capitaltrabalho.

$\mathrm{Na}$ área da Psicologia Escolar, por sua vez, Maluf (1994) considerou que se encontravam em profundas revisões e reformulações os "esquemas conceituais que sustentaram a formação em Psicologia durante o curso de graduação" (p.166) que estavam provocando mudanças na atuação na referida área. Particularmente, destaca o questionamento à concepção de adaptação de criança à escola e um novo olhar ao fenômeno educativo como fruto das relações escolares e institucionais. A autora também se refere à atuação do psicólogo, cuja defesa nos anos 1990 é de que atue como um profissional independente do corpo administrativo da escola. De um modo geral, as mudanças incidiram a partir de uma crítica ao modelo psicométrico de avaliação, bem como ao papel do psicólogo na escola e em contextos educacionais diversos. Defende um novo olhar que não priorize apenas a "criança-problema" (individualizante) como era dito anteriormente, mas todo o contexto sociopolítico e cultural no qual se insere, assim como a realidade escolar brasileira e os pressupostos históricos envolvidos na produção dos problemas neste âmbito.

Esses três importantes trabalhos revelam as mudanças significativas que aconteceram no plano da discussão teórico-metodológica nas três principais áreas de atuação da Psicologia e como tais mudanças deveriam estar também presentes na formação. Não queremos dizer com isso que a prática profissional antecede a formação, mas que os movimentos sociais e políticos vigentes, as questões postas socialmente pelo momento político, histórico e social da profissão passaram a questionar a atuação e a formação profissional, exigindo novas respostas e enfrentamentos para a profissão no Brasil. Analisaremos, em seguida, as saídas que se fizeram presentes no plano da formação profissional apontadas pela pesquisa recente na área.

\section{A formação do Psicólogo nas novas Diretrizes Curriculares}

As discussões a respeito da formação profissional no campo da Psicologia se mantiveram durante a década de 1990 (Machado, 1996; Meira, 1997; Souza, 1996; Tanamachi, 1997; Yazzle, 1997) fortalecidas pela busca de uma identidade profissional articulada com os novos desafios sociais. Mais especificamente, essas discussões desembocaram na articulação nacional que norteou a elaboração das Diretrizes Curriculares para o Curso de Graduação em Psicologia, cujas ideias são discutidas no bojo da nova Lei de Diretrizes e Bases da Educação Nacional (LDBEN). Sobre tais discussões, destacam-se o livro organizado por Guzzo (2001, 2002), fruto de debates construídos no interior do Grupo de Trabalho em Psicologia Escolar da Associação Nacional de Pesquisa e Pós-Graduação em Psicologia, e o trabalho de Yamamoto (2000).

As Diretrizes comparecem no cenário nacional oficialmente em 2004, trazendo mudanças bastante significativas em relação ao Currículo Mínimo, em seus princípios, objetivos e metas, circunscritas ao modelo dos Parâmetros Curriculares Nacionais, centradas na concepção construtivista de aprendizagem. Nesta perspectiva teórico-metodológica, o currículo deverá ser construído tendo em vista a aquisição de competências e habilidades para a formação e o exercício profissional. Dentre as inovações previstas, destaca-se a ruptura com a concepção de áreas de atuação profissional no interior da formação. As áreas tradicionais (Psicologia Clínica, Escolar e Organizacional) deveriam ser substituídas por ênfases curriculares, a serem escolhidas por alunos nos últimos períodos do curso e tais ênfases poderiam ter inclusive aspectos de duas ou mais áreas interligadas.

Segundo as Diretrizes Curriculares Nacionais para a área de Psicologia, o que se espera de uma formação profissional em Psicologia pelas Instituições de Ensino Superior do Brasil é que esteja voltada para a atuação profissional, 
pesquisa e ensino de Psicologia, assegurando determinados princípios e compromissos, a saber: a) Construção e desenvolvimento do conhecimento científico em Psicologia; b) Compreensão dos múltiplos referenciais que buscam apreender a amplitude do fenômeno psicológico em suas interfaces com os fenômenos biológicos e sociais; c) Reconhecimento da diversidade de perspectivas necessárias para compreensão do ser humano e incentivo à interlocução com campos de conhecimento que permitam a apreensão da complexidade e multideterminação do fenômeno psicológico; d) Compreensão crítica dos fenômenos sociais, econômicos, culturais e políticos do País, fundamentais ao exercício da cidadania e da profissão; e) Atuação em diferentes contextos considerando as necessidades sociais e os direitos humanos, tendo em vista a promoção da qualidade de vida dos indivíduos, grupos, organizações e comunidades; f) Respeito à ética nas relações com clientes e usuários, com colegas, com o público e na produção e divulgação de pesquisas, trabalhos e informações na área da Psicologia; g) Aprimoramento e capacitação contínuos.

Estes princípios e compromissos detalham as questões apontadas por Ancona-Lopez em Parecer emitido em 2004, enfatizando que as Diretrizes Curriculares em Psicologia deverão contemplar uma formação ampla do psicólogo, respeitando "a multiplicidade de suas concepções teóricas e metodológicas, originadas em diferentes paradigmas e modos distintos de compreender a ciência, assim como a diversidade de suas práticas e contextos vários de atuação" (Parecer CNE/CES, Ancona-Lopez, 2004).

Mas como garantir que haja, em nível nacional, uma formação básica, comum aos cursos de Psicologia, em diferentes regiões e necessidades locais? Como garantir uma formação que responda aos compromissos e princípios estabelecidos pelas Diretrizes Curriculares Nacionais? Esta questão é resolvida no interior do Documento por meio da criação de um núcleo comum, definido como "um conjunto de competências básicas que se reportam a desempenhos e atuações iniciais requeridas do formando em Psicologia" (Parecer CNE/CES, Ancona-Lopez, 2004). Estes "visam garantir ao profissional o domínio de conhecimentos psicológicos e a capacidade de utilizá-los em diferentes contextos que demandam a investigação, análise, avaliação, prevenção e intervenção em processos psicológicos" (Ancona Lopez, 2004).

Portanto, segundo as Diretrizes, a formação em Psicologia exige que a proposta do curso articule os conhecimentos, habilidades e competências em torno dos seguintes eixos estruturantes: fundamentos epistemológicos e históricos; fundamentos teórico-metodológicos; procedimentos para a investigação científica e a prática profissional; fenômenos e processos psicológicos; interfaces com campos afins do conhecimento e práticas profissionais, estas voltadas para assegurar um núcleo básico de competências que permitam a atuação profissional e inserção do graduado em diferentes contextos institucionais e sociais, de forma articulada com profissionais de áreas afins.
Quanto ao conceito de ênfases, a proposta das novas Diretrizes busca garantir, em consonância com um núcleo comum, algumas das especificidades presentes no campo da Psicologia, possibilitando a constituição de competências profissionais e de habilidades acadêmicas descritas neste documento. Segundo Bastos (2002), este conceito é inovador por possibilitar a constituição de espaços de aprofundamento que complementam a formação básica e que "devem surgir da vocação da instituição ou de demandas sociais emergentes da realidade em que ela se insere" (p. 41).

Neste sentido, a noção de ênfase curricular propõe a superação da visão dualista de formação profissional centrada na polaridade generalista versus especialista. Esta discussão teve início nos anos 1990, e encontra-se presente em Souza (1996), quando discute que uma forma de superação desta dualidade exigiria a construção de "princípios norteadores de uma prática a serviço de pensarmos a exclusão, a estigmatização e a desigualdade" (p. 243), temáticas consideradas como fundamentais na constituição de um compromisso ético e político do profissional psicólogo frente aos desafios sociais.

\section{A dimensão educativa na formação profissional}

No que tange à atuação do psicólogo no campo da educação, as discussões iniciadas nos anos 1980 tiveram excelentes resultados e muitos se articulam com as questões postas pelas Diretrizes Curriculares, como procuramos apresentar a seguir.

A Psicologia Escolar e Educacional tem suscitado inúmeras reflexões acerca da formação e da prática dos profissionais que nela atuam, sobretudo a necessidade de redefinição do papel do psicólogo na escola e de reestruturação de sua formação acadêmica (Almeida, 1999; Balbino, 1990, 2007; Checchia \& Souza, 2003; Cruces \& Maluf, 2007; Del Prette, 2001, 2002; Gomes, 2002; Guzzo, 2001, 2002; Jobim \& Souza, 1996; Joly, 2000; Maluf, 1994; Marinho-Araújo, 2007; Martins, 1994, Meira, 2002; Novaes, 2002; Souza, 1996; Wechsler, 1996; Witter 1997, 2002; Yazlle, 1990).

Segundo Novaes (2002), "o surgimento de novos espaços e tempos educativos provocará, sem dúvida, mudanças não só no próprio sistema educacional e social como nas práticas profissionais do psicólogo escolar." (p. 98). Afirma a autora que não podemos continuar vislumbrando o futuro como uma mera continuidade do passado ou até mesmo do presente, pois nos encontramos diante de uma crise histórica que "exige novas soluções para novos problemas". Neste sentido, afirma que "o psicólogo escolar terá que procurar caminhos outros para ajudar a construir esse novo século que já está em nossas portas." (p.101).

Para Gomes (2002), a Psicologia Escolar também precisa acompanhar a realidade atual: "Considerando que a sala de aula reflete a sociedade, é urgente que a Psicologia Escolar transforme cada vez mais o foco de interesse" (p. 50); para isto, "será necessário repensar a Universidade que, por um lado, desenvolve pesquisas e aprimora os conhecimentos na área e, por outro, não prepara profissionais capazes 
de enfrentar o desafio de promover Educação e Saúde no ambiente escolar." (p. 71).

Checchia e Souza (2003) consideram ainda que a formação profissional deva, nesta área, favorecer "a realização de uma prática de atendimento psicológico que busque a ruptura do fracasso escolar, (...) considerando a complexidade das práticas envolvidas na vida escolar" (p. 125). Para as autoras, a Psicologia no campo da dimensão educativa do trabalho do psicólogo tem construído os elementos constitutivos para uma atuação e uma formação em uma perspectiva crítica. Analisam que tal construção baseia-se no tripé: a) compromisso da Psicologia com a luta por uma escola democrática e com qualidade social; b) ruptura epistemológica relativa à visão adaptacionista de Psicologia; e c) construção de uma práxis psicológica frente à queixa escolar (p. 126).

Mas como aproximar as questões postas na área da Psicologia Escolar e Educacional e os desafios das Diretrizes Curriculares em Psicologia? Marinho-Araújo (2007) tenta fazer esse exercício de análise e de aproximação entre as discussões instaladas na área e os desafios das Diretrizes Curriculares. Um primeiro aspecto destacado pela autora é a necessidade de clareza em relação ao perfil profissional esperado do egresso do Curso de Psicologia. Ou seja, que psicólogo desejamos formar? Segundo a autora, a implantação das Diretrizes requer "a construção de um perfil crítico e comprometido com a transformação das condições sociais e de trabalho que permeiam o contexto escolar e educacional" (p. 20), porém destaca que este perfil deve articular-se "coletivamente e defendendo a utilidade das intervenções, como suporte ao reconhecimento social da profissão" (MarinhoAraújo, 2007, p. 20).

Portanto, quando articulamos o perfil indicado com as questões postas pela área, conforme analisa a autora, estaremos nos comprometendo com uma formação que se encontra articulada a concepções que estarão na direção da busca pela cultura de sucesso escolar, por novas concepções sobre o desenvolvimento humano, na direção da complexidade de sua definição, substituindo paradigmas como o da doença e do tratamento pelo da saúde psicológica e da construção de estratégias que visem à promoção e ao bem estar humanos. É no interior desse quadro conceitual que a presente pesquisa se insere buscando compreender a apropriação possível, presente no campo da formação em Psicologia, no que tange a sua dimensão educativa, tal como posto nas Diretrizes Curriculares Nacionais do MEC para a área.

\section{Metodologia da pesquisa}

Este estudo assume uma abordagem qualitativa, do tipo estudo de caso (Lüdke \& André, 1986; Stake, 2000) e compreende duas grandes fases na obtenção dos dados: documental e empírica, partindo do pressuposto que a realidade social é subjetiva e objetiva ao mesmo tempo, múltipla, dinâmica, resultado de uma construção dos sujeitos participantes, mediante a interação com outros membros da sociedade.
Com relação à fase documental, os procedimentos metodológicos adotados foram: levantamento da literatura produzida na área da Psicologia Escolar e Educacional, que redefine a formação/atuação do psicólogo no campo educacional em uma perspectiva multiprofissional, educativa, em consonância com as Diretrizes Curriculares Nacionais para os Cursos de Graduação em Psicologia; levantamento e análise de documentos oficiais do curso de Psicologia pesquisado.

Os procedimentos metodológicos no estudo empírico foram: elaboração e validação dos instrumentos de coleta de dados (questionário padronizado e entrevistas gravadas); levantamento e análise do discurso do coordenador de curso e professores de Psicologia da IES estudada, que ministram disciplinas e estágios curriculares vinculados à ênfase em "processos educativos e à atuação do psicólogo no campo da educação"; levantamento e análise do discurso de alunos do $4^{\circ}$ e $5^{\circ}$ anos de Psicologia desta IES quanto aos elementos que compõem o pensamento e a prática docente universitária no que se refere à atuação do psicólogo no campo da educação, bem como a análise estatística (estatística descritiva) dos dados quantitativos encontrados.

$\mathrm{Na}$ análise e tratamento dos dados coletados adotamos os procedimentos interpretativos da informação textual (Bardin, 2000) e posterior aplicação da estratégia de triangulação (Denzin, citado por Silverman, 2009).

\section{Resultados e discussão}

Os resultados apresentados neste estudo contemplam informações decorrentes da coleta de dados nas fases documental e empírica da pesquisa. Eles estão distribuídos em quadros/matrizes descritivos, além da ilustração com gráficos e relacionam-se, em sua grande maioria, com os discursos produzidos pelo questionário aplicado aos alunos, bem como pelas entrevistas com docentes e coordenador do curso de Psicologia da IES estudada.

\section{Formação de psicólogos em Rondônia}

O curso de Psicologia no Estado de Rondônia teve o seu início em 1988, com a Licenciatura em Psicologia pela Universidade Federal de Rondônia - UNIR e, somente em 1991, é criada a habilitação em Formação do psicólogo, naquela mesma IFES. Atualmente, o curso já formou aproximadamente 300 psicólogos nestes quase 30 anos de existência, contando com um corpo docente qualificado e, recentemente, teve o curso de mestrado em Psicologia criado e recomendado pela CAPES (2009). Na sequência, vamos traçar um perfil da expansão desta formação em Rondônia, dando destaque à formação de psicólogos na UNIR.

\section{Expansão dos cursos de Psicologia em Rondônia.}

Tomando por base o Censo da Educação Superior de 2004, o mesmo registrou 2.013 instituições de educação superior (IES) no país, sendo que 118 delas (5,8\%) estão 
Quadro 1. Perfil da expansão dos cursos de Psicologia em Rondônia.

\begin{tabular}{|c|c|c|c|c|}
\hline IES & $\begin{array}{l}\text { Identificação/ } \\
\text { Localização }\end{array}$ & $\begin{array}{l}\text { Início curso/ } \\
\text { Habilitação }\end{array}$ & $\begin{array}{l}\text { Carga horária/ } \\
\text { Vagas/Turnos }\end{array}$ & Ênfases \\
\hline UNIR & $\begin{array}{l}\text { Universidade Federal } \\
\text { de Rondônia (1982). } \\
\text { Sede em Porto Velho, } \\
\text { mais } 06 \text { campi no } \\
\text { interior do Estado }\end{array}$ & $\begin{array}{l}1988 \text { (1991) } \\
\text { Licenciatura e } \\
\text { Formação do } \\
\text { Psicólogo }\end{array}$ & $\begin{array}{l}4545 \mathrm{~h} \\
30 \text { anuais } \\
\text { Diurno (integral) }\end{array}$ & $\begin{array}{l}\text { Educação e } \\
\text { Desenvolvimento } \\
\text { Organizacional e } \\
\text { Trabalho } \\
\text { Saúde Mental e } \\
\text { Prevenção }\end{array}$ \\
\hline ILES/ULBRA & $\begin{array}{l}\text { Instituto Luterano de } \\
\text { Ensino Superior de } \\
\text { Porto Velho (1998) }\end{array}$ & $\begin{array}{l}2004 \\
\text { Bacharel e } \\
\text { Formação do } \\
\text { Psicólogo } \\
\end{array}$ & $\begin{array}{l}4.440 \mathrm{~h} \\
200 \text { anuais } \\
\text { Noturno }\end{array}$ & $\begin{array}{l}\text { Psicologia Escolar } \\
\text { Psicologia Clínica } \\
\text { Psicologia Jurídica }\end{array}$ \\
\hline FACIMED & $\begin{array}{l}\text { Faculdade de Ciências } \\
\text { Biomédicas de Cacoal }\end{array}$ & $\begin{array}{l}2005 \\
\text { Licenciatura e } \\
\text { Formação do } \\
\text { Psicólogo }\end{array}$ & $\begin{array}{l}4500 \mathrm{~h} \\
100 \text { anuais } \\
\text { Matutino e Noturno }\end{array}$ & $\begin{array}{l}\text { Educação e } \\
\text { Desenvolvimento } \\
\text { Humano } \\
\text { Saúde Mental, } \\
\text { Psicossocial e Prevenção } \\
\text { Psicologia Social e do } \\
\text { Trabalho }\end{array}$ \\
\hline FAAR & $\begin{array}{l}\text { Faculdades } \\
\text { Associadas de } \\
\text { Ariquemes (2000) }\end{array}$ & $\begin{array}{l}2006 \\
\text { Formação do } \\
\text { Psicólogo }\end{array}$ & $\begin{array}{l}4220 \mathrm{~h} \\
100 \text { anuais } \\
\text { Noturno }\end{array}$ & $\begin{array}{l}\text { Psicologia } \\
\text { Organizacional } \\
\text { Psicologia da Saúde }\end{array}$ \\
\hline FAROL & $\begin{array}{l}\text { Faculdade de Rolim } \\
\text { de Moura (2003) }\end{array}$ & $\begin{array}{l}2007 \\
\text { Formação do } \\
\text { Psicólogo }\end{array}$ & $\begin{array}{l}4440 \mathrm{~h} \\
100 \text { anuais } \\
\text { Noturno }\end{array}$ & $\begin{array}{l}\text { Processos Clínicos } \\
\text { Processos Educativos } \\
\text { Processos de Prevenção } \\
\text { e Promoção da Saúde }\end{array}$ \\
\hline IESA/FAMA & $\begin{array}{l}\text { Instituição de Ensino } \\
\text { Superior da Amazônia/ } \\
\text { Faculdade da } \\
\text { Amazônia (Vilhena) }\end{array}$ & $\begin{array}{l}2006 \\
\text { Bacharel e } \\
\text { Formação do } \\
\text { Psicólogo }\end{array}$ & $\begin{array}{l}4500 \mathrm{~h} \\
100 \text { anuais } \\
\text { Diurno e Noturno }\end{array}$ & $\begin{array}{l}\text { Educação } \\
\text { Clínica e Saúde }\end{array}$ \\
\hline
\end{tabular}

Fonte: Sites das IES na Internet, 2009.

localizadas na região Norte e o Estado de Rondônia possui 22 IES, ou seja, 18,6\% das instituições desta região, sendo apenas uma pública $(4,5 \%)$ e as restantes privadas $(95,5 \%)$ (INEP, 2006). Cabe destacar que existe uma única IES com organização acadêmica de universidade, qual seja, a Universidade Federal de Rondônia - UNIR, fundada em 1982, juntamente com a criação do Estado de Rondônia. Quanto às outras IES, 17 são particulares com fins lucrativos e 04 são Comunitárias, Filantrópicas e/ou Confessionais (INEP, 2006).

O processo de expansão pode ser observado a partir da aprovação da LDB (1996), quando houve uma ampliação de $118,3 \%$ no número de IES no país e mais que o dobro na região Norte (247\%), sendo que em Rondônia o aumento foi de $175 \%$, maior que o apresentado nacionalmente. Esta expansão no Estado de Rondônia efetiva-se a partir de 1997, quando há uma ampliação de 07 para 21 IES privadas, permanecendo apenas uma IFES até o ano de 2006, quando foi criada a Escola Agrotécnica Federal de Colorado do Oeste (EAFCO), que, atualmente, transformou-se em Instituto Tecnológico. Apesar da Universidade Federal de Rondônia ser a única universidade pública em Rondônia, ela é a responsável por aproximadamente $40 \%$ do número de cursos de graduação oferecidos em todo o Estado. Quanto ao oferecimento do curso de Psicologia, sua expansão pode ser constatada no Quadro 1.

Com base na leitura deste quadro, do ponto de vista da expansão do Ensino Superior em Rondônia, constatamos que o número de cursos de Psicologia passou de um para seis num curto espaço de tempo, ou seja, no período de 2004 
a 2007 houve um aumento de $600 \%$ no oferecimento da formação neste Estado. Já com relação à habilitação, os novos cursos priorizam a formação do psicólogo e apenas um deles oferece a formação de professor em Psicologia, conforme a nova orientação das diretrizes curriculares nacionais. Em nível nacional, os dados de $2007^{10}$ revelam que havia no país 356 cursos de psicologia, sendo 56 em IES públicas e 300 particulares, e a maior concentração deles está localizada na região Sudeste, totalizando 165 cursos.

No tocante às ênfases curriculares, o quadro acima revela uma prevalência no âmbito da saúde em $100 \%$ dos cursos, com destaque para a saúde mental, priorizando modelos de atuação centrados na prevenção e na promoção. Entretanto, é importante ressaltar que a Educação se faz presente em $83 \%$ dos cursos, articulada principalmente com desenvolvimento humano, sendo que um deles permanece com a perspectiva tradicional da nomenclatura de área (Psicologia Escolar). Constatamos também que apenas um curso buscou incluir a nova nomenclatura de processos educativos em suas ênfases, seguindo as orientações presentes nas Diretrizes Curriculares para a área. Quanto ao número de horas destinadas à formação do psicólogo, observamos que há uma homogeneidade entre os cursos, variando de 4.220 horas a 4.545 horas, e o turno predominante nos novos cursos é o noturno, com um oferecimento de vagas em torno de 100 por ano.

Diante do apresentado, podemos afirmar que a expansão dos cursos de Psicologia é patente no Estado de Rondônia, no âmbito do Ensino Superior Privado, como também há uma presença significativa da ênfase na formação do psicólogo para atuar com a dimensão educativa, o que demonstra um compromisso das IES com a educação básica no Estado.

Bernardes (2003), em seu artigo "O debate atual sobre a formação em Psicologia no Brasil - análise de documentos de domínio público", preocupava-se com esta expansão no número de cursos (47\%), que ocorre a partir de 1990, mais especificamente nos últimos cinco anos desta década. O autor destacava o contexto em que vivíamos na época e defendia que a formação em Psicologia era central para a pesquisa, basicamente em função de vários fatores, a saber: "a ausência de reformas curriculares, o psicologicismo que marca a sociedade [...] e o processo de mercantilização do ensino no país, visualizado no crescente número de cursos de Psicologia abertos nas últimas décadas" (Bernardes, 2003 , p. 20). Mas é importante considerar a desigualdade regional da oferta de cursos superiores, especialmente na região norte do país, justificando a ampliação dessa modalidade de ensino.

\section{Panorama da formação em Psicologia na UNIR}

A formação em Psicologia na Universidade Federal de Rondônia realiza-se no campus situado na cidade de Porto Velho, capital do Estado, sendo que a UNIR conta com mais seis campi, localizados nas principais cidades de Rondônia,

10 Dados obtidos na BVS - PSI, 2007. a saber: Cacoal, Vilhena, Ji-Paraná, Rolim de Moura, Ariquemes e Guajará-Mirim. O curso conta com uma matriz curricular vigente desde 1996; entretanto seu projeto pedagógico vem passando por modificações, discussões e avaliação desde o ano de 2005, quando foi designada uma Comissão para fazer sua reformulação, em decorrência da aprovação das Novas Diretrizes Curriculares Nacionais do MEC (2004).

Produto do trabalho desta Comissão, o documento que está disponível no site da universidade demonstra que há uma disposição em oferecer uma formação mais voltada para a dimensão social e para o desenvolvimento científico da área, conforme ilustram os fragmentos a seguir: "O presente projeto propõe um curso de Formação de Psicólogo que espelha o compromisso com o desenvolvimento social e da ciência, [...] com a responsabilidade de educar cidadãos para uma sociedade em mudança e, sobremaneira, esteja sensível às demandas sociais". Além disso, "Um curso capaz de inovar a presença da Psicologia em Porto Velho e arredores, capaz de buscar sempre romper com doutrinas e políticas de exclusão e alienação social, impondo presença em novas áreas do fazer psicológico" (2005, s/p).

Consta também neste documento que o projeto do curso está em processo de reformulação e aprovação nas instâncias competentes da universidade, o que é confirmado nas falas dos professores entrevistados, ainda que estejam em discordância em alguns aspectos: "Como disse, ainda não implantamos efetivamente a matriz [...]". (Esta resposta foi dada revendo a matriz curricular proposta para o Curso de Psicologia da UNIR, que pretendemos ver implantada em 2010) (P1, 2009); "[...] nosso curso ainda não está seguindo as orientações das Diretrizes Curriculares; no momento, uma Comissão está redigindo nossa nova matriz curricular com base nas diretrizes e com base no que ficou decidido no Fórum de Discussão das Diretrizes" (P2, 2009);

O projeto pedagógico em vigor já contém os termos ou nomenclaturas quanto à organização curricular de núcleos comuns e eixos estruturantes para estar adequado às Novas Diretrizes, porém o conteúdo ainda não. O formato, o modelo é esse, mas ainda não se chegou à essência (P3, 2007).

Percebe-se, nos exemplos acima, que há um projeto reformulado e que está disponível no site desta IFES, mas existe também um movimento interno de reelaboração do mesmo, com vistas a adequá-lo aos anseios dos vários segmentos envolvidos neste processo, como fica evidente na fala de uma das professoras entrevistadas:

A construção da Matriz Curricular assentada nas Diretrizes de 2004 teve uma linda construção. Os professores vinham discutindo uma proposta de matriz, quando os alunos propuseram um Seminário de Discussão. Os alunos se prepararam, estudaram as diretrizes e as propostas de matriz feita pelos professores e de outras universidades. Os professores e alunos defendiam suas ideias, algumas disciplinas foram retiradas, outras incluídas, cargas horárias ampliadas ou diminuídas [...] (P1, 2009). 
Quadro 2. Perfil dos alunos de Psicologia da UNIR.

\begin{tabular}{|l|l|l|}
\hline Gênero/Estado Civil & $\begin{array}{l}\mathrm{F}-72 \% \\
\mathrm{M}-28 \%\end{array}$ & $\begin{array}{l}\text { Solteiro }-94,4 \% \\
\mathrm{NR}=5,6 \%\end{array}$ \\
\hline Naturalidade & $\begin{array}{l}\text { RO }-55,5 \% \\
\text { Outros Estados }-44,5 \%\end{array}$ & AM/ GO/MT/ MA/ RN/ PB/ SP \\
\hline \multirow{2}{*}{ Ensino Médio } & $\begin{array}{l}\text { Rede de Ensino: } \\
\text { Público }-33 \% \\
\text { Privado }-67 \%\end{array}$ & $\begin{array}{l}\text { Ano conclusão: NR=6\% } \\
1985-1999-11 \% \\
2000-2004-83 \%\end{array}$ \\
\hline Acesso à Universidade & $\begin{array}{l}\text { Número de Vestibular: } \\
01-38,8 \%\end{array}$ & $\begin{array}{l}\text { Ano de ingresso: } \\
2002-5,6 \% \\
2004-22,2 \% \\
2005-72,2 \%\end{array}$ \\
\hline Moradia/Transporte & $\begin{array}{l}\text { Família }-83,3 \% \\
\text { República }-5,6 \% \\
\text { Outra }-11,1 \%\end{array}$ & $\begin{array}{l}\text { Carro }-50 \% \\
\text { Onibus }-22,2 \% \\
\text { Carro+Ônibus }-16,6 \% \\
\text { NR }-11,2 \%\end{array}$ \\
\hline Trabalho/Ocupação & $\begin{array}{l}\text { Não }-77,8 \% \\
\text { Sim }-22,2 \%\end{array}$ & Brinquedista/Funcionário público \\
\hline
\end{tabular}

Fonte: Questionário aplicado na pesquisa de campo, 2008.

O exemplo relatado corrobora com Ribeiro e Silva (2007) quando afirmam que "os tópicos que geraram mais discussões foram os que implicavam alterações estruturais ou modificações mais significativas que afetassem a organização e a carga horária das disciplinas ao longo do curso e a carga horária total do curso." (p.8).

\section{Perfil dos alunos pesquisados}

A coletividade estudada caracteriza-se como sendo os alunos do $4^{\circ}$ ano ( $8^{\circ}$ período) do curso de Psicologia da UNIR. A amostra está composta por 18 alunos (num total de 22 alunos matriculados naquele período no ano de 2008).

O Quadro 2, auxilia-nos a conhecer o perfil desses alunos, permitindo-nos afirmar que eles são, em sua maioria, solteiros, do sexo feminino (72\%), egressos da rede privada de ensino e que concluíram sua escolarização básica na última década. Quanto ao gênero, Castro e Yamamoto (1998) relataram os resultados das pesquisas de Ferretti (1976) e Lewin (1980), que encontraram, respectivamente, os percentuais de $87,1 \%$ e $86 \%$ para o predomínio das mulheres na formação em Psicologia no país. Dados corroborados por Mello (1975) (82,9\%); e pelo Conselho Federal de Psicologia (2004), que chegam a encontrar que $91 \%$ dos psicólogos entrevistados eram mulheres, demonstram que a Psicologia é um curso eminentemente feminino.

Constatamos também que a maioria deles mora com suas famílias, não trabalha e a metade utiliza o carro para ir à universidade. Cabe também destacar que a metade deles nasceu em Rondônia, prestou pelo menos dois vestibulares, sendo que $72 \%$ ingressaram no Ensino Superior no ano de 2005 , ou seja, os alunos pesquisados estão cursando o período esperado, o que demonstra aprovação nos semestres anteriores.

Buscamos conhecer também os principais motivos que os levaram a escolher o curso de Psicologia, quais sejam: a busca pela realização pessoal e para ter acesso a um curso universitário, ficando em terceiro plano a realização profissional. A influência de familiares e/ou amigos não aparece em destaque, ainda que seja indicado como decisivo para a escolha do curso.

\section{Dados sobre o processo formativo}

Dos 18 alunos pesquisados, $67 \%$ responderam que enfrentavam dificuldades durante seu processo formativo e destacam a falta de relacionar teoria e prática dentro do currículo. Esta constatação também se evidencia no discurso de docentes do curso, conforme ilustrações, a seguir:

Penso que o aspecto mais positivo e que aponta desenvolvimentos nas diretrizes é o fato de aliar, desde o projeto, a parte prática das disciplinas, não ficando mais à vontade dos professores. Mais do que isto, nos obriga a pensar criativamente em experiências práticas, pois ninguém iria aguentar um curso inteiro de observação e entrevistas. (P1, 2009). 


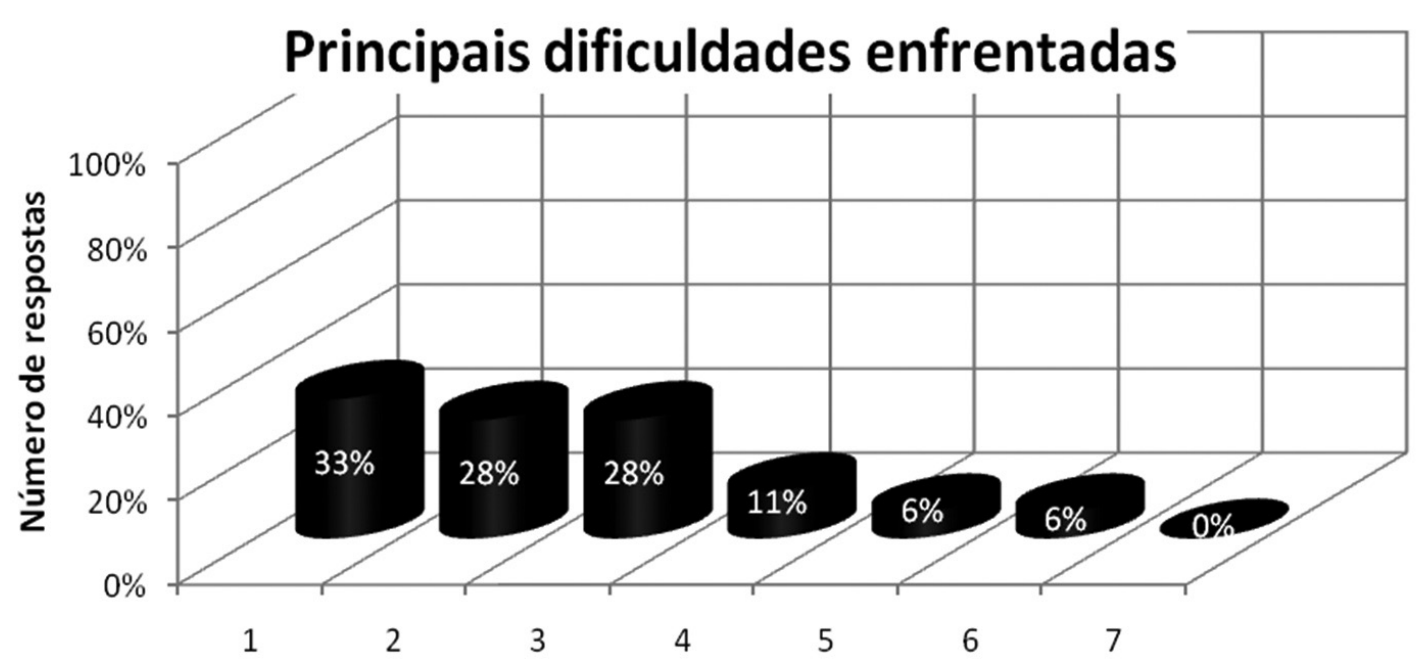

1 - Relacionar teoria e prática dentro do currículo da formação do psicólogo

5 - Dominar a retórica e as técnicas da produção científica

2 - Coordenar os estudos universitários e o trabalho profissional

6 - Insuficiência prévia dos conhecimentos da área de formação básica do curso

7 - Acompanhar a dinâmica dos estudos

3 - Conciliar formação, trabalho e família universitários

4 - Relação com os colegas de curso

Principais dificuldades enfrentadas, considerando as duas primeiras opções mais apontadas Número total de participantes: 12 alunos (67\% da amostra)

Figura 1. Gráfico das principais dificuldades enfrentadas pelos alunos durante sua formação em Psicologia.

Fonte: Questionário aplicado na pesquisa de campo, 2008.

A professora entrevistada reconhece as dificuldades presentes nas novas diretrizes quanto à inserção da prática nas disciplinas do núcleo comum, que foram anunciadas pelos alunos pesquisados:

\section{[...] confesso que ainda não sabemos como vamos articular isto dinamicamente na formação de nosso aluno, mas, assim como a diretriz, é nosso esforço de planejar uma nova postura de formação profissional, fruto daquilo que temos percebido como falta em nossa prática social. (P1, 2009).}

Na Figura 1, estão relacionadas todas as dificuldades apresentadas pelos alunos e o percentual de respostas encontrado.

Na Figura 2, no âmbito das relações interpessoais, os alunos avaliam como muito deficiente (83\%), na sua forma- ção, o quantitativo de docentes em função das disciplinas do currículo, o que pode, de certa forma, estar relacionado com o não atendimento por parte dos docentes às dificuldades por eles apresentadas, resultado também destacado nesta figura.

Contudo, os alunos consideram extremamente positivo o compromisso tanto dos docentes quanto deles próprios com a formação acadêmica, além da qualidade e da capacidade que os professores demonstram possuir para promover o desenvolvimento da formação profissional em Psicologia.

Em se tratando de competências e habilidades propostas pelas novas Diretrizes Curriculares para a área - uma das principais mudanças na formação do psicólogo -, encontramos neste estudo, ver Figura 3, que "realizar orientação, aconselhamento psicológico e psicoterapia" foi a competência adquirida mais destacada pelos alunos (61\%). Também $56 \%$ deles, ou seja, mais da metade do grupo pesquisado, 


\section{Quanto ao âmbito das relações interpessoais}

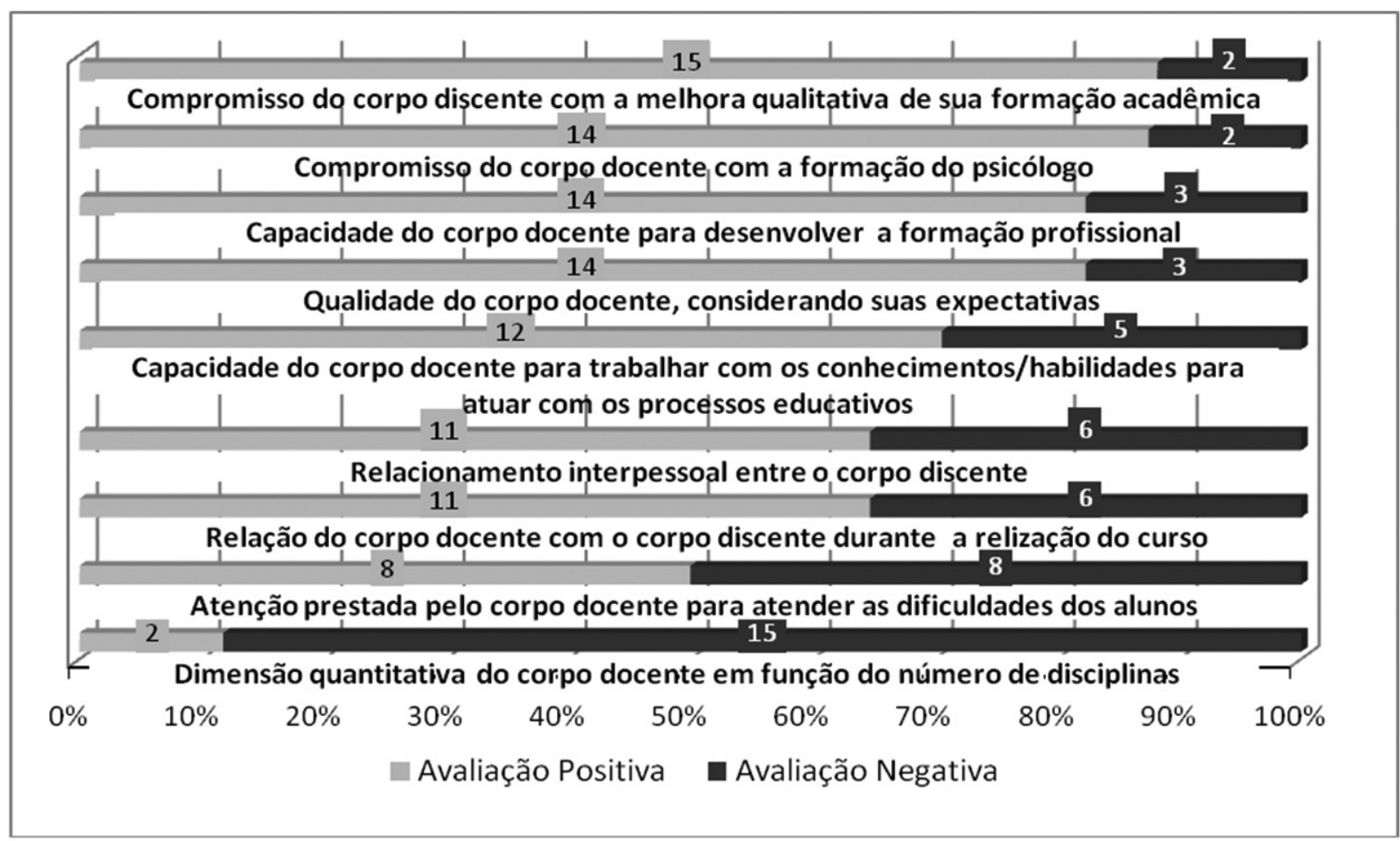

Figura 2. Gráfico da avaliação dos alunos quanto ao âmbito das relações entre discentes e docentes no curso de Psicologia.

Fonte: Questionário aplicado na pesquisa de campo, 2008.

afirmaram saber "relacionar-se com o outro de modo a propiciar o desenvolvimento de vínculos interpessoais requeridos na sua atuação profissional"; "avaliar fenômenos humanos de ordem cognitiva, comportamental e afetiva em diferentes contextos" e "analisar o contexto em que atua profissionalmente em suas dimensões institucional e organizacional, explicitando a dinâmica das interações entre os seus agentes sociais", levando-nos a inferir que há uma forte tendência da formação em uma abordagem clínica e organizacional. Contudo, há competências e habilidades que são apontadas como insuficientes nesta formação, com destaque para "saber buscar e usar o conhecimento científico necessário à atuação profissional, assim como gerar conhecimento a partir da prática profissional" (33\%). O que só vem corroborar com a principal dificuldade apresentada anteriormente.

Brasileiro e Albuquerque (2008), estudando o curso de licenciatura em psicologia, no período de 2005 a 2006, nesta mesma instituição e com a participação de alguns alunos da atual pesquisa, encontraram resultados semelhantes quanto à competência avaliar fenômenos humanos de ordem cognitiva, comportamental e afetiva em diferentes contextos, também destacada neste estudo de 2008. Este fato reitera dados obtidos no último Exame Nacional do Desempenho do Estudante (ENADE, 2006), que afirmam que os melhores resultados obtidos pelos alunos quanto aos conteúdos específicos centram-se no eixo estruturante denominado Processos Psicológicos (Souza, Bastos, \& Barbosa, 2009), ao qual esta competência está relacionada.

No tocante ao nível de satisfação dos alunos quanto aos âmbitos estrutural, operativo e curricular da formação em Psicologia nesta IFES, a Fgura 4 apresenta os aspectos que foram por eles avaliados positiva e negativamente.

Merece destaque, nesta figura, a avaliação extremamente positiva que os alunos fazem em relação ao âmbito curricular quanto: à adequação das disciplinas oferecidas em relação às competências necessárias para a formação profissional e à contribuição das disciplinas para a formação do psicólogo para atuar com os processos educativos, chegando a um nível de satisfação em torno de 90\%. Este dado demonstra que, apesar do curso estar em processo de reestruturação para atender às orientações das novas diretrizes, o currículo consegue satisfazer as necessidades de formação dos alunos.

Quanto ao âmbito operacional, podemos observar que três indicadores aparecem com um nível mediano de satisfação: as condições oferecidas para a integração teoria prática, para a realização das atividades práticas e a adequação do acervo bibliográfico da UNIR às necessidades do curso de Psicologia. É importante considerar que dois destes estão relacionados a uma das dificuldades a ser solucionada 


\section{DESENVOLVIMENTO DAS COMPETÊNCIAS GERAIS}

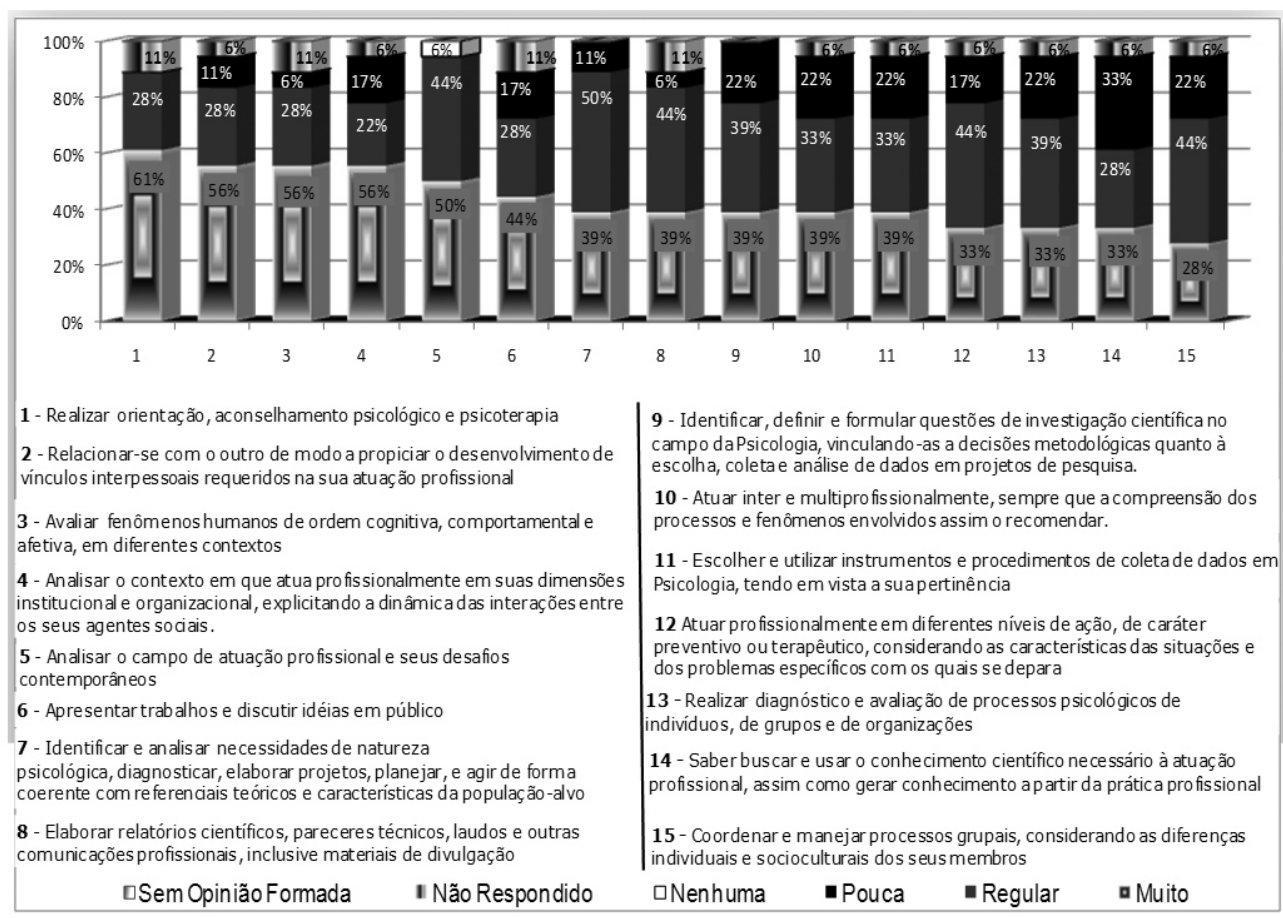

Número total de participantes: 18 alunos

Figura 3. Gráfico das competências e habilidades gerais desenvolvidas pelos alunos durante sua formação em Psicologia.

Fonte: Questionário aplicado na pesquisa de campo, 2008.

nesta formação, apontada pelos alunos em outros itens do instrumento aplicado no estudo empírico, qual seja: a relação teoria prática na formação do psicólogo nesta IFES. Problemática corroborada pelas entrevistas realizadas com professores e coordenador deste curso, quando afirmam que "Faltam às diretrizes indicações de como articular os conteúdos, as informações, na formação deste profissional" (P1, 2009); "Mediante a realidade de nossas universidades, principalmente a nossa, com um número reduzido de professores, colocarmos em prática essa diretriz não será fácil, porque supervisionar as atividades práticas previstas na diretriz vai ser um desafio" (P2, 2009); "Estamos pleiteando para que cada disciplina, cada setor, consiga realmente viabilizar, articular esse conhecimento teórico com a prática, promover ações específicas na formação de cada profissional, é o que a gente encontra no núcleo comum" (C, 2009).

No tocante ao desagrado dos alunos pesquisados, a ênfase recai na adequação das tecnologias disponíveis, principalmente as novas tecnologias e suas ferramentas virtuais. Este é um problema crônico, apontado por Brasileiro e Albuquerque (2008), não caracterizando uma questão específica para a formação de psicólogos na UNIR. Talvez este possa ser um dos motivos que leva estes alunos a considerarem negativamente o compromisso da instituição com sua formação acadêmica.

\section{Considerações finais}

As recentes publicações no campo da Psicologia Escolar têm demonstrado mudanças, como as propostas nas Diretrizes, que são complexas e exigem a apropriação, por parte do formador, de novas concepções em relação à estrutura do curso, ao perfil profissional dos egressos desejados e à maneira de estabelecer relações significativas entre teoria e prática no contexto curricular e da prática pedagógica.

Neste estudo, buscamos conhecer como está ocorrendo este processo dentro de uma IFES da região Norte, com a intenção de demonstrar que estes desafios estão presentes na formação de psicólogos no país. Assim, os resultados encontrados nos levam a algumas considerações:

a) quanto ao projeto pedagógico do curso pesquisado, o mesmo está em fase de reestruturação, buscando adequar-se às novas Diretrizes Curriculares Nacionais para a área (MEC, 2004). Segundo seus professores e o coordenador de curso entrevistados, há concordância nas contribuições trazidas por estas Diretrizes para uma formação de psicólogos mais ampla. Entretanto, destacam dificuldades na definição das ênfases e a contradição generalista $X$ especialista, presente nas atuais Diretrizes;

b) quanto à percepção do processo formativo pelos alunos, a maioria afirma enfrentar dificuldades, principal- 


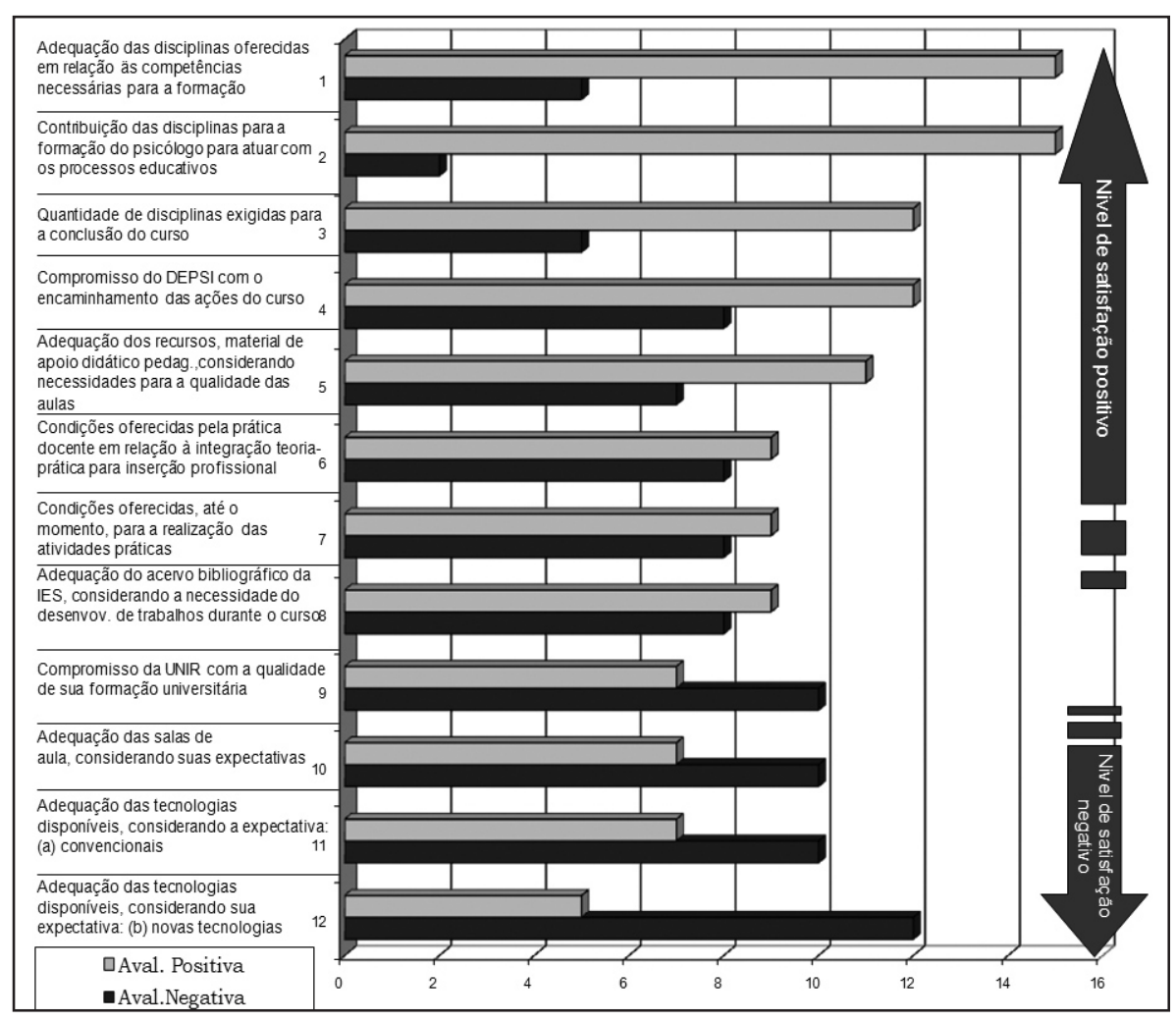

Figura 4. Gráfico do nível de satisfação dos alunos em relação aos âmbitos estrutural, operativo e curricular da formação em Psicologia.

Fonte: Questionário aplicado na pesquisa de campo, 2008.

mente para relacionar teoria e prática dentro do currículo da formação de psicólogo; dizem estar mais preparados para realizar orientação, aconselhamento psicológico e psicoterapia, assim como avaliar fenômenos humanos de ordem cognitiva, comportamental e afetiva, em diferentes contextos; porém sentem-se inseguros para atuar profissionalmente em diferentes níveis de ação, de caráter preventivo ou terapêutico, considerando as características das situações e dos problemas específicos com os quais se deparam. O que nos leva a considerar a natureza dos estágios e das práticas veiculadas, podendo indicar uma tendência a modalidades de formação profissional centradas em modelos de clínicaescola e laboratorial;

c) quanto ao nível de satisfação em relação aos vários âmbitos do curso, os alunos destacam o compromisso com a melhoria qualitativa de sua formação acadêmica, além de considerarem os docentes compromissados e aptos para realizar sua formação, ainda que denunciem a sua carência em número, o que dificulta o atendimento às suas necessidades de aprendizado; elogiam o currículo do curso, considerandoo adequado às diretrizes, inclusive quanto à sua formação para atuar com os processos educativos. Entretanto, destacam dificuldades institucionais com as condições físicas e materiais para uma educação superior de qualidade.
Consideramos que pesquisar questões desta natureza, embora não esgote a questão, colabora na importante tarefa de avaliação e de indicação de caminhos que venham a ser trilhados por aqueles que formam psicólogos em âmbito nacional e este estudo vem se somar a esta iniciativa de demais pesquisadores brasileiros.

\section{Referências}

Almeida, M. J. (1999). Educação Médica e Saúde: Possibilidades de Mudança. Londrina/Rio de Janeiro: Ed. UEL/ABEM.

Ancona-Lopez, M., \& Maranhão, E. (2004). Parecer CNE/CES $n$. 0062/2004 - Diretrizes Curriculares de Psicologia. Disponível: http://www.anaceu.org.br/legislacao/pareceres_cne/parecer_05. html.

Balbino, V. R. (1990) Psicólogos escolares em Fortaleza: dados da formação, da prática e da contextualização da atividade profissional. Revista Psicologia, ciência e Profissão, 2(4), 50-56.

Balbino, V. R. (2007). Psicologia e Psicologia Escolar no Brasil. São Paulo: Summus Editorial. 
Bardin, L. (2000). Análise de conteúdo. Lisboa: Edições.

Bastos, A. V. B. (2002). Perfis de formação e ênfases curriculares: o que são e por que surgiram? In: Revista do Departamento de Psicologia - UFF, 14(1), 31-58.

Bastos, A. V. B., \& Achcar, R. (Coord.). (1994). Psicólogo brasileiro: práticas emergentes e desafios para a formação. São Paulo: Casa do Psicólogo.

Bernardes, J. S. (2003). O debate atual sobre a formação em psicologia no Brasil - análise de documentos de domínio público. Revista Estudos e Pesquisas em Psicologia, UERJ, 3(2). Recuperado: 02 mar. 2009. Disponível: http://revispsi.uerj.br/ v3n2/artigos/comunictesev3nehtml

Brasileiro, T. S. A, \& Albuquerque, D. B. (2008). A formação inicial de professores na UNIR: aproximações a uma realidade amazônica. Em T. S. A. Brasileiro, A. A. Colares \& M. L. I. S. Colares (Orgs.), Pesquisa educacional na Amazônia: relatos de iniciação científica (CNPq/PIBIC) em Rondônia. Campinas, SP: Alínea.

Campos, H. R. (2007). Formação em Psicologia Escolar: realidades e perspectivas. Campinas, SP: Alínea.

Castro, A. E. F., Yamamoto, O. H. (1998). A psicologia como profissao feminina: apontamentos para estudo. Estudos de Psicologia 3(1), 147-158.

Checchia, A. K. A., \& Souza, M. P. R. (2003). Queixa escolar e atuação profissional: apontamentos para a formação de psicólogos. Em M. E. M. Meira \& M. Antunes, Psicologia Escolar: teorias críticas (pp.105-138). São Paulo: Casa do Psicólogo.

Conselho Federal de Psicologia. (1990). Relatório final da pesquisa sobre o perfil do psicólogo brasileiro. Disponível: http://pepsic. bvs-psi.org.br/scielo.php?script=sci_arttext\&pid=S141498932004000300007\&lng=pt\&nrm=

Cruces, A. V. V., \& Maluf, M. R. (1996). Psicólogos recém-formados: oportunidades de trabalho e atuação na área educacional. Em H. R. Campos. (Org.), Formação em Psicologia Escolar - realidades e perspectivas (pp. 163-210). Campinas, SP: Alínea.

Del Prette, Z. A. P. (Org.). (2001). Psicologia Escolar e educacional: Saúde e qualidade de vida. Campinas, SP: Alínea.

Del Prette, Z. A. P. (2002). Psicologia, educação e LDB: novos desafios para velhas questões? Em R. S. L. Guzzo (Org.), Psicologia Escolar: LDB e Educação Hoje (2a. ed.) (pp. 11-34). Campinas, SP: Alínea.

Ferretti, C. J. (1996). A mulher e a escolha vocacional. Cadernos de Pesquisa, p. 34-46.
Gomes, V. L. T. (2002). A formação do psicólogo e os impasses entre a teoria e a prática. Em R. S. L. Guzzo (Org.), Psicologia Escolar. LDB e Educação Hoje (2a. ed.) (pp. 49-73). Campinas, SP: Alínea.

Guzzo, R. S. L. (2001). Formando psicólogos escolares no Brasil: dificuldades e perspectivas. Em S. M. Wechssler (Org.), Psicologia Escolar: Pesquisa, formação e prática (pp. 75-92). Campinas, SP: Alínea.

Guzzo, R. S. L. (2002). Novo paradigma para formação e atuação do Psicólogo escolar no cenário educacional brasileiro. R. S. L. Guzzo (Org.), Psicologia Escolar: LDB e Educação Hoje (2a. ed.). Campinas, SP: Alínea.

INEP. (2006). Educação Superior Brasileira 1991-2004. Rondônia, Brasília.

Jobim e Souza, S. (1996). O psicólogo na educação: identidade e transformação. Coletâneas da ANPEPP, 7, 37-45.

Joly, M. C. A. (2000). A formação do psicólogo escolar e a educação no terceiro milênio. Psicologia Escolar e Educacional, 4(2), 5155.

Lei 4119, de 27 de agosto de 1962. (1962, 27 de agosto). Dispõe sobre os cursos de formação em Psicologia e regulamenta a profissão de Psicólogo. Brasília.

Lei 5766, de 20 de dezembro de 1976. (1976, 20 de dezembro). Cria o Conselho Federal e os Conselhos Regionais de Psicologia e dá outras providências. Brasília.

Lewin, H. (1980). Educação e força de trabalho feminino no Brasil. Cadernos de Pesquisa, 32, 45-59.

Lo Bianco, A. C., Bastos, A. V. B., Nunes, M. L. T., \& Silva, R. C. da. (1994). Concepções e atividades emergentes na psicologia clínica: implicações para a formação. Em Conselho Federal de Psicologia, Psicólogo Brasileiro: práticas emergentes e desafios para a formação (pp. 7-79). São Paulo: Casa do Psicólogo.

Ludke, M., \& André, M. (1986). Pesquisa em educação: abordagens qualitativas. São Paulo: EPU.

Marinho-Araújo, C. M. (2007). A Psicologia Escolar nas Diretrizes Curriculares. Em H. Campos (Org.), Formação em Psicologia Escolar: realidades e perspectivas (pp. 17-48). Campinas, SP: Alínea.

Machado, A. M. (1996). Crianças de Classe Especial. São Paulo: Casa do Psicólogo.

Maluf, M. R. (1994). Formação e atuação do Psicólogo na educação: dinâmica de transformação. Em CFP Psicólogo Brasileiro: Práticas emergentes e desafios para a formação (pp. 157-200). São Paulo: Casa do Psicólogo. 
Martins, J. B. (1994). O disciplinamento escolar e a prática do psicólogo escolar. Em J. B. Martins (Org.), Psicologia e Educação: tecendo caminhos (pp. 95-120). São Carlos, SP: Rima.

Meira, M. E. M. (1997). Psicologia Escolar: Pensamento Crítico e Práticas Profissionais. Tese de Doutorado, Instituto de Psicologia, Universidade de São Paulo, São Paulo.

Meira, M. E. M. (2002). Psicologia Escolar: pensamento crítico e práticas profissionais. Em E. R. Tanamachi, M. Proença \& M. Rocha (Orgs.), Psicologia e Educação: Desafios teórico-práticos (pp. 73-104). São Paulo: Casa do Psicólogo.

Mello, S. L. de. (1975). Psicologia e profissão em São Paulo. São Paulo: Ática.

Novaes, M. H. (2002). A convivência em novos tempos e espaços educativos. Em R. S. L. Guzzo (Org.), Psicologia Escolar: LDB e Educação Hoje (2a. Ed). Campinas, SP: Alínea.

Parecer 0062/2004. (2004, 19 de fevereiro). Fixa as Diretrizes Curriculares Nacionais para os cursos de graduação em Psicologia. Brasília: Ministério da Educação, Conselho Nacional de Educação/ Câmara de Educação Superior.

Patto, M. H. S. (1981). Psicologia e ideologia: reflexões sobre a psicologia escolar. Tese de Doutorado, Instituto de Psicologia, Universidade de São Paulo, São Paulo.

Resolução CFP No 006/2007. (2007). Institui o código de processamento disciplinar. Disponível: pol.org.br/legislacao/doc/ resolucao2007_6.doc

Ribeiro, M. P. O, \& Silva, M. C. V. M. (2007). Análise de um processo de reformulação curricular no ensino superior. Revista E-Curriculum, 3(1). Recuperado: 24 ago. 2009. Disponível: http:// www.pucsp.br/ecurriculum

Silverman, D. (2009). Interpretação de dados qualitativos. Métodos para análise de entrevistas, textos e interações (3a ed.). Porto Alegre: Artmed.

Souza, M. P. R. (1996). A queixa escolar e a formação do psicólogo. Tese de Doutorado, Instituto de Psicologia, Universidade de São Paulo, São Paulo.

Souza, M. P. R. (2002). A queixa escolar e a formação do psicólogo: desafios e perspectivas. Em E. R. Tanamachi, M. Proença \& M. Rocha (Orgs.), Psicologia e Educação: Desafios teórico-práticos (pp. 73-104). São Paulo: Casa do Psicólogo.
Souza, M. P. R., Bastos, A. V., \& Barbosa, D. R. (2009). A formação básica e profissional do psicólogo: uma análise do desempenho dos alunos no ENADE 2006. Mimeo.

Stake, R. E. (2000). Case Studies. Em N. K. Denzin \& Y. S. Lincoln, Handboock of Qualitative Research (2 ${ }^{\text {nd }}$ ed.). Califórnia: Sage Publications.

Tanamachi, E. R. (1997). Visão crítica de Educação e de Psicologia: Elementos para a construção de uma visão crítica de Psicologia Escolar. Tese de Doutorado, UNESP, Marília, São Paulo.

Tanamachi, E. R. (2002). Mediações teórico-práticas de uma visão crítica em Psicologia Escolar. Em E. R. Tanamachi, M. Proença \& M. Rocha (Orgs.), Psicologia e Educação: Desafios teóricopráticos (pp. 73-104). São Paulo: Casa do Psicólogo.

Wechsler, S. M. (1996). Psicologia Escolar. Pesquisa, Formação e Prática. Campinas, SP: Alínea.

Witter, G. P. (1997). O Psicólogo Escolar: Pesquisa e Ensino. Tese de Livre Docência, Instituto de Psicologia, Universidade de São Paulo, São Paulo.

Witter, G. P. (2002). Psicólogo no ensino superior e a Lei de Diretrizes e Bases. Em R. S. L. Guzzo (Org.), Psicologia Escolar. LDB e Educação Hoje (2a. ed.). Campinas, SP: Alínea.

Yamamoto, O. H. (2000). A LDB e a psicologia. Psicol. cienc. prof. [online], 20(4), 30-37. Disponível: http://pepsic.bvs-psi.org.br/ scielo.php?script=sci_arttext\&pid=S141498932000000400004\& $\mathrm{ng}=\mathrm{es} \& \mathrm{nrm}$

Yazlle, E. G. (1990). A formação do psicólogo escolar no estado de São Paulo - subsídios para uma ação necessária. Tese de Doutorado, Pontifícia Universidade Católica de São Paulo.

Yazlle, E. G. (1997). A atuação do psicólogo escolar: alguns dados históricos. Em B. B. B. Cunha, Psicologia na escola: um pouco de história e algumas histórias. São Paulo: Arte Ciência. 
Recebido em: 24/09/2009

Reformulado em: 25/05/2010

Aprovado em: 26/05/2010

\section{Sobre as autoras}

Tânia Suely Azevedo Brasileiro (taniabrasileiro@gmail.com)

Universidade Federal de Rondônia, Porto Velho, RO

Marilene Proença Rebello de Souza (mprdsouz@usp.br)

Instituto de Psicologia da Universidade de São Paulo, São Paulo, SP

\section{Correspondência}

Marilene Proença Rebello de Souza

Instituto de Psicologia da Universidade de São Paulo

Laboratório Interinstitucional de Estudos e Pesquisas em Psicologia Escolar - LIEPPE

Av. Prof. Mello Moraes 1721 Sala 19 Bolco G

CEP 05508-030 Cidade Universitária - São Paulo - SP

\section{Agradecimento}

Ao CNPq pelo apoio com Bolsa de Pós-Doutorado Júnior.

A Alex Moreira do Carmo. 